\title{
The Alternative Model of Personality Disorders (AMPD) from the Perspective of the Five-Factor Model
}

\author{
Thomas A. Widiger Gillian A. McCabe \\ Department of Psychology, University of Kentucky, Lexington, KY, USA
}

\section{Keywords}

DSM-5 - Alternative Model of Personality Disorders - AMPD · Five-Factor Model · Personality disorders . Personality traits

\begin{abstract}
The fifth edition of the American Psychiatric Association's (APA) Diagnostic and Statistical Manual of Mental Disorders (DSM-5; American Psychiatric Association. Diagnostic and Statistical Manual of Mental Disorders. 5th ed. Washington: American Psychiatric Association; 2013) includes an Alternative Model of Personality Disorders (AMPD). The AMPD includes two components: the Criterion A level of personality functioning (i.e., impairments or deficits in the sense of self and interpersonal relatedness) and the Criterion B five-domain maladaptive trait model. The purpose of the current paper is to discuss the AMPD from the perspective of the Five-Factor Model (FFM) of general personality structure. The conclusion of this review is that both the Criterion A selfother deficits and the Criterion $B$ traits can be understood as maladaptive variants of the FFM.

(c) 2020 S. Karger AG, Basel
\end{abstract}

\section{The Alternative Model of Personality Disorders from the Perspective of the Five-Factor Model}

The fifth edition of the American Psychiatric Association's (APA) Diagnostic and Statistical Manual of Mental Disorders (DSM-5; [1]) includes an Alternative Model of Personality Disorders (AMPD). The AMPD includes two components: (1) the Criterion A level of personality functioning (LPF; i.e., impairments or deficits in the sense of self and interpersonal relatedness) and (2) the Criterion B five-domain maladaptive trait model. The AMPD is a significant step toward the development of a dimensional trait model conceptualization of personality disorders (PDs) that will provide a more accurate, complete, and clinically useful description of a patient's personality, facilitating thereby patient-therapist communication and treatment planning [2-4]. The purpose of this paper is to discuss the AMPD from the perspective of the Five-Factor Model (FFM) of general personality structure. Both the Criterion A LPF and the Criterion B maladaptive trait model will be considered. We begin with a discussion of the relationship of the Criterion B traits with the FFM, as this relationship is relatively more straightforward.

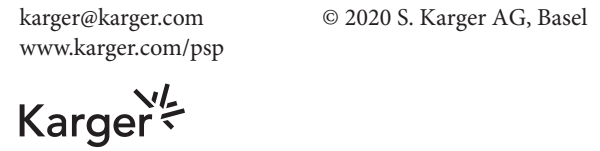

Thomas A. Widiger, PhD

Department of Psychology University of Kentucky, 115 Kastle Hall Lexington, KY 40506-0044 (USA) widiger@uky.edu 


\section{Criterion B: Maladaptive Personality Traits}

The FFM is the predominant dimensional model of general personality structure $[5,6]$, consisting of the five broad domains of neuroticism (or emotional instability versus stability), extraversion (versus introversion), openness (or unconventionality), agreeableness (versus antagonism), and conscientiousness (or constraint versus disinhibition). The DSM-5 AMPD trait model includes the domains of negative affectivity, detachment, psychoticism, antagonism, and disinhibition [1]. As stated in the DSM-5, these "five broad domains are maladaptive variants of the five domains of the extensively validated and replicated personality model known as the "Big Five," or the Five Factor Model of personality" [1, p. 773].

It should be acknowledged though that when the trait model was first posted on the DSM-5 website in 2010 (consisting at that time of six domains), it was not aligned with the FFM. On the contrary, Clark and Krueger [7] explicitly distanced the DSM-5 trait model from the FFM, stating that compulsivity (which was included as a sixth domain) did not align with FFM conscientiousness and that schizotypy (which eventually became the psychoticism domain) did not align with FFM openness. For some, this gave the appearance that the model was created de nova (i.e., was not aligned with any existing trait model) and was not well grounded in the considerable body of prior FFM research $[8,9]$. As expressed by Shedler et al. [10] in their American Journal of Psychiatry editorial objecting to the trait model, "the resulting model no longer rests on decades of research, which had been the chief rationale for including it" (p. 1027). However, in the end, the DSM-5 trait model was aligned with the FFM [1, p. 773]. As affirmed by Krueger and Markon [11], the DSM-5 trait "domains can be understood as maladaptive extremes of the five-factor model (FFM) that has usefully framed extensive research in the field of personality and individual differences" (p. 480).

The FFM traces its roots to the Big Five, a trait model derived from a factor analysis of virtually every trait term within the English and other languages [12]. To the extent that the Big Five includes every maladaptive trait term, it naturally follows that the FFM, aligned with the Big Five, accounts for virtually every maladaptive personality trait [6]. There is indeed a substantial body of research documenting that the FFM accounts for all of the DSM-IV PDs $[2,3]$. Multiple persons who have reviewed the FFM-PD research have reached the conclusion that all of the PDs can be understood as maladaptive variants of the FFM (e.g., $[4,13-15])$.
There are also now quite a few studies documenting the alignment of the DSM-5 trait model with the FFM (e.g., [16-26]). One point of dispute though has been the alignment of psychoticism with openness. Some studies have reported essentially no relationship (e.g., [24, 25, 27]); and even for many of the studies that have reported a relationship, the strength of the association has been relatively weak (e.g., $[17,19-21])$. It is evident that the strength of the relationship of psychoticism with FFM openness depends substantially on how both openness and psychoticism are defined and/or assessed [28].

\section{Openness}

Costa and McCrae [29] began with just a three-factor model. Once they became aware of the Big Five, they expanded their model to include the domains of antagonism and conscientiousness, assessed by the NEO Personality Inventory-Revised (NEO PI-R; [30]). However, they did not revise their measure of neuroticism, extraversion, or openness to be optimally aligned with the respective Big Five domains of emotional instability, surgency, and intellect, respectively. This was not a problem for neuroticism and extraversion as they were already very closely congruent with the Big Five domains of emotional instability and surgency, but Costa and McCrae had conceptualized openness to emphasize ideal personality traits of self-actualization, an open mind, and selfrealization, citing humanism papers and texts. This was not how the respective domain (i.e., intellect) was conceptualized within the Big Five. There was certainly a strong convergence of FFM openness with Big Five intellect, but there were also important differences. Big Five intellect is more heavily predominated by such traits as unconventionality, eccentricity, and nonconforming, along with an openness to values and feelings [31].

Alternative measures and models of openness have been developed for which a clearer relationship with schizotypal thinking has been more readily apparent, including the Odd and Eccentric scale developed by Piedmont and colleagues [32], Openness/Intellect within the Big Five Aspects scale [33], the Absorption scale within the 5-Dimensional Personality Test (5-DPT; [34]), the Unconventionality scale within the HEXACO-Personality Inventory (HEXACO-PI; [35]), and the Unconventionality domain within the Inventory of Personal Characteristics-5 (IPC-5; [36]). Tellegen [37] in fact suggested years ago with respect to his unconventionality conceptualization of openness that "markers of this type are clinically suggestive, particularly of schizotypal personality disorder" (p. 126). 
The studies that have obtained the weakest relationship of openness with psychoticism have typically relied on a NEO inventory or a closely comparable measure (e.g., $[22,25,27])$. Positive results have been more consistently obtained with the alternative measures of openness (e.g., $[19,23,38-42])$. For example, Gore and Widiger [20] conducted a joint factor analysis of the Personality Inventory for DSM-5 (PID-5; [43]) that assessed the DSM-5 dimensional trait model, along with the IPC-5 of Tellegen and Waller [36] and the 5-DPT of van Kampen [34], as well as the NEO PI-R [30]. The optimal solution was a five-factor model, with an openness-psychoticism factor defined heavily by IPC-5 Unconventionality, 5-DPT Absorption, and PID-5 Psychoticism, as well as (but more weakly) by NEO PI-R Openness.

\section{Psychoticism}

The conceptualization and assessment of psychoticism is equally important [28]. The DSM-5 trait model organizes the maladaptive traits included within the DSM-IV PDs into the five trait domains [1]. DSM-5 AMPD antagonism, for example, includes traits from the narcissistic and antisocial PDs, as well as the paranoid, schizotypal, and (to a lesser extent) borderline. Psychoticism would be comparably defined largely by the cognitive, behavioral, and perceptual aberrations of the schizotypal PD (e.g., magical thinking and odd-eccentric behavior). The original name for this domain was indeed schizotypy [4]. However, the PID-5 assessment of psychoticism includes overt psychotic delusions. Schizotypal personality traits (e.g., eccentricity and magical ideation) are on a continuum with psychotic delusions, but there are important differences between a personality trait and a delusion. A fundamental and defining feature of a personality trait (and a PD) is an early onset and a largely chronic presence thereafter, whereas a delusion can appear at any point in a person's life and will be limited in its duration. Delusions are not typically understood to be personality traits and are not included within the diagnostic criteria for schizotypal PD [1]. Delusions are part of acute psychotic episodes.

Nevertheless, the PID-5 includes delusions within two of the three subscales (i.e., Cognitive and Perceptual Dysregulation and Unusual Beliefs and Experiences; PID-5 Eccentricity does not include any references to delusions). Three sample items are "Sometimes I feel 'controlled' by thoughts that belong to someone else," "Sometimes I think someone else is removing thoughts from my head," and "Sometimes I can influence other people just by sending my thoughts to them." And, these are not just

Five-Factor Model and AMPD mild delusions, these are Schneiderian delusions of thought control and thought broadcasting [44], considered at one time to be pathognomonic for schizophrenia and still considered today to represent the most severe forms of delusions $[1,44]$, well beyond the pathology evident within a schizotypal PD.

Crego and Widiger [40] administered the three PID-5 Psychoticism scales along with the three corresponding scales from the Five Factor Schizotypal Inventory (FFSI [45]; i.e., FFSI Aberrant Ideas, Aberrant Perceptions, and Odd and Eccentric). None of the FFSI scales includes references to delusions or hallucinations. Also included were two personality trait scales: IPIP-NEO Imagination [46] and IPC-5 Unconventionality [36] that assess for Big Five openness. All three of the FFSI schizotypal cognition-perception scales obtained medium to large effect size relationships with the personality traits of imagination and unconventionality, whereas PID-5 Cognitive and Perceptual Dysregulation and PID-5 Unusual Beliefs and Experiences were largely uncorrelated with the FFM traits. PID-5 Eccentricity, which does not include any references to psychotic delusions, did obtain medium to large effect size relationships with the FFM traits. In a joint factor analysis, the three FFSI schizotypal cognitionperception scales, PID-5 Eccentricity, IPIP-NEO Imagination, and IPC-5 Unconventionality defined a distinct openness-schizotypal factor, whereas PID-5 Cognitive and Perceptual Dysregulation and PID-5 Unusual Beliefs and Experiences, including the psychotic items, separated to form their own distinct factor. These results were closely replicated in a separate data collection, this time including HEXACO PI-R Unconventionality (instead of IPC-5 Unconventionality), along with the three FFSI schizotypal cognition-perception scales, the three PID-5 psychoticism scales, and IPIP-NEO Imagination [40].

\section{Conclusions}

In sum, the DSM-5 AMPD trait model can be understood as an instantiation of FFM PD [8]. There are, of course, other possible maladaptive trait models derived from the FFM. The FFM includes all possible maladaptive personality traits, with clearly many, many more traits than are included just within the DSM-5 Criterion B AMPD. Coker et al. [31] identified 803 maladaptive trait terms within the English language, and further indicated that there are maladaptive traits at both poles of all five domains of the FFM. Crego et al. [47] provide an FFM maladaptive trait model that illustrates the presence of maladaptive trait scales at both poles for all five domains. The absence within the DSM-5 trait model of maladap- 
tive variants of agreeableness, conscientiousness, extraversion, and low neuroticism has limited its ability to adequately cover all of the important DSM-IV PDs [48]. It is perhaps also worth noting that FFM maladaptive trait models have typically placed some of the DSM-5 traits within different locations than provided by the DSM-5 AMPD (e.g., depressivity within neuroticism rather than detachment, and suspiciousness within antagonism rather than detachment $[17,24])$. Nevertheless, the DSM-5 Criterion B AMPD is well understood to be providing a maladaptive variant of FFM general personality structure [8].

\section{Criterion A: LPF}

The principal authors of the LPF [49], as well as others (e.g., [50]), consider the Criterion A self-other impairments to represent something different, if not largely distinct, from maladaptive personality traits. The LPF traces its roots to psychodynamic theory in which PDs are believed to be the result of core deficits in the sense of self and interpersonal relatedness [51]. This is not though the viewpoint of proponents of the FFM (e.g., [52]) or authors of other trait models (e.g., [53]). It is also noteworthy that the DSM-5 AMPD was preceded by three preparatory conferences, none of which included any reference to a need for a self-other deficits domain when defining PD. At all three conferences, the trait model was considered to be comprehensive and sufficient in its coverage of the PDs (i.e., [54-56]).

To the extent that an impaired sense of self reflects a characteristic or consistent expression of the self, it would naturally be considered to be a personality trait. "Personality traits are enduring patterns of perceiving, relating to, and thinking about the environment and oneself" [1, p. 647]. A characteristically inaccurate or distorted sense of self is an example of an enduring pattern of perceiving and thinking about oneself. As stated by the authors of Criterion A, "The deficits ... are likely to result from processes of temperament, development, and environment that have been shown to influence how an individual typically views himself or herself and others" [49, p. 333]. Indeed, some of the DSM-5 Criterion A impairments and Criterion B traits are virtually identical [57]. For example, there is no meaningful distinction between a "lack of concern for feelings, needs, or suffering of others; lack of remorse after hurting or mistreating another" [1, p. 764] and a "lack of concern for feelings or problems of others; lack of guilt or remorse about the negative or harmful ef- fects of one's actions on others" [1, p. 764]. The former is a Criterion A self-impairment and the latter is a Criterion B trait.

Morey [58], a co-author of the Criterion A deficits, has in fact acknowledged that there is "a substantial saturation of Criterion A impairment in (the) Criterion B constructs" (p. 1197). Of course, from his perspective, this is a problem with how the traits are defined. He suggests that the Criterion A content should be removed from the Criterion B traits. However, this would be removing (for instance) lack of empathy from antagonism or lack of self-directedness from disinhibition, deleting traits from the dimensional trait model.

Psychodynamic constructs have long been accounted for within the FFM. For example, McCrae et al. [59] demonstrated how the 100 items within the psychodynamic California Q-Set are well understood within the FFM. Mullins-Sweatt and Widiger [60] similarly indicated that the items within the Shedler-Westen Assessment Procedure-200 fall within the FFM. The original DSM-5 Section III prototype narratives, which heavily informed the Criterion A deficits, were modeled closely after the SWAP-200 [61].

The Five Factor Borderline Inventory (FFBI [62]), an FFM maladaptive trait measure of borderline PD (BPD), includes a scale for Self-Disturbance (assessing distortions in the sense of self and identity) that has been shown to be a variant of FFM neuroticism. Livesley and Jackson, the former also being an author of the Criterion A deficits, had similarly included a scale for Identity Problems within their historically influential trait measure, the Dimensional Assessment of Personality Pathology-Basic Questionnaire (DAPP-BQ [63]). DAPP-BQ Identity Problems is placed within their trait domain of emotional dysregulation that is closely aligned with FFM neuroticism. Subsequent research has consistently verified the location of these scales as facets of the trait domain of negative affectivity and/or neuroticism (e.g., [64]).

There have also now been a number of studies addressing the question of whether there is a meaningful distinction between Criterion A and B [57, 65]. This research has consistently indicated very large effect size relationships of alternative measures of Criterion A with maladaptive personality traits (e.g., [66]). Some studies have even shown no meaningful incremental validity of Criterion A LPF over Criterion $B$ traits in accounting for $P D$ variance (e.g., [52]), whereas the Criterion $B$ traits routinely obtained considerable incremental validity [65]. Of course, there are also some studies indicating incremental validity of an LPF measure over a maladaptive personality trait 
(e.g., [67]). However, in these studies the common variance is far, far larger than the unique variance (e.g., [68]).

In addition, incremental validity may not actually address optimally the question of distinctness. If a measure lacks incremental validity, then clearly it is not providing any new, unique information. Incremental validity though is simply indicating that some of the variance within the criterion measure is uniquely accounted for. Maladaptive personality traits have also been shown to obtain incremental validity over normal FFM traits in accounting for PD variance; yet, these traits are still readily understood as falling within the FFM personality structure $[4,11]$. Even measures of precisely the same constructs will often obtain incremental validity over one another in accounting for an external validator [69]. Any measure of a construct will typically have at least some unique variance that is specific to that measure. In sum, obtaining incremental validity may not be a strong method for documenting distinctiveness, particularly when the unique variance is quite small relative to the shared variance.

More informative are studies that address whether the deficits and traits can or cannot be understood as falling within a common latent structure. For example, Berghuis et al. [70] submitted to a factor analysis the correlations among the scales of a measure of the FFM (i.e., the NEO PI-R [30]) and measures of Criterion A deficits; more specifically, the General Assessment of Personality Disorders (GAPD) and the Severity Indices for Personality Problems-118 (SIPP-118). The NEO PI-R scales did load substantially on and helped to define six of the seven factors. The interpersonal deficit scales loaded within FFM antagonism and introversion factors, and self-directedness scales loaded with low conscientiousness. Nevertheless, Berghuis et al. [70] still concluded that their results indicated that the Criterion A deficits and the FFM involved "clearly distinct components of personality" [p. 704]. This conclusion was based on the finding that one of the four components of Criterion A, identity disturbance, did separate to form its own factor (ignoring that three of the four did not). Indeed, the Self-Identity factor was not at all defined by any NEO PI-R scales. It was confined instead to 19 scales of self-pathology (15 from the GAPD and 4 from the SIPP-118).

Oltmanns and Widiger [71] though subsequently indicated that the identity disturbance results of Berghuis et al. [70] illustrated the phenomenon of a bloated specific factor. Berghuis et al. had included a large number of scales assessing alternative forms of self-pathology (i.e., 15 from the GAPD and 4 from the SIPP-118). Even if these scales assess components of neuroticism, they would likely correlate much more highly with one another than with other facets of neuroticism, such as angry hostility. If one facet of neuroticism is much more heavily represented by multiple scales relative to the others, the respective scales of that facet will bind together to yield a factor independent of the other facets. Oltmanns and Widiger [71] demonstrated that the self-pathology scales of the GAPD separated from neuroticism when an excessive number were included, but loaded within neuroticism when this facet was not represented disproportionately relative to the other facets of neuroticism, consistent with the research concerning the identity disturbance scales of the FFBI [62] and DAPP-BQ [47, 63].

Bifactor analysis is a structural analysis in which the first factor extracted is a general factor representing what is shared by most or all of the scales. The subsequent specific factors concern remaining variance not shared with the general factor. A bifactor analysis is appealing to those who believe that the general factor concerns the core of $\mathrm{PD}$ (e.g., what is common to all PDs) that is also distinct from the remaining PD variance.

For example, Sharp et al. [72] considered the covariation among the diagnostic criteria for the six DSM-IV PDs included within the DSM-5 Section III AMPD. An exploratory bifactor analysis yielded a general factor of personality disorder (g-PD), along with six specific factors. They noted that all the BPD criteria loaded solely on the g-PD. Sharp et al. therefore suggested that the g-PD was a substantive representation of the DSM-5 Section III AMPD Criterion A. "Although we do not yet know the exact nature of the general factor, to stimulate further research, we speculate on some intriguing interpretative possibilities ... One answer may lie in Criterion A of the new DSM-5III General Criteria of Personality Disorder" [72, p. 394]. $\mathrm{BPD}$ is the only PD that explicitly includes identity deficits within its criterion set. "BPD is unique in that impairment in the ability to maintain and use benign and coherent internal images of self and others are integrated into (this) one disorder" [72, p. 394]. Wright et al. [73] obtained comparable findings and reached the same conclusion.

However, both Sharp et al. [72] and Wright et al. [73] did not appear to appreciate that only one of the nine diagnostic criteria for BPD concerns identity disturbance. The BPD criteria largely defined the g-PD in these two studies, but the BPD criteria also include affective instability, unstable and intense relationships, self-harm, recurrent suicidal behavior, frantic efforts to avoid abandonment, transient paranoid ideation, dissociation, impulsivity (e.g., substance usage, binge eating), and inappropriate intense anger. These additional features 
also define the g-PD and have little to nothing to do with an impairment in the sense of self.

Oltmanns et al. [74] further demonstrated that the g-PD correlates substantially with the general factors of personality and psychopathology, calling into question the proposal that the g-PD is defined by the LPF self-other deficits. The LPF deficits in identity would not also define what is common to such "Axis I" disorders as schizophrenia, bipolar mood disorder, substance use, and panic disorder, nor would the LPF define what is common to all normal personality traits; yet, the three general factors share a substantial amount of common variance. Oltmanns et al. [74] suggest that the three general factors are not defined by the personality traits, PDs, or "Axis I" disorders, but by the common social-occupational impairments and distress that are secondary to these traits and disorders. It is the level of nonspecific impairment that determines one's relative position on general factors (e.g., level of occupational dysfunction), not the presence of a particular disorder or trait that causes this disfunction (e.g., laxness or perfectionism that results in occupational dysfunction).

One can normally interpret a factor by the items obtaining the highest loadings. In the case of the general factor, however, the highest loading variables will be those that involve the most dysfunction. In the case of the $\mathrm{g}-\mathrm{PD}$, this will typically be borderline traits as they are the most impairing relative to the other PDs (e.g., $[72,73])$, whereas in the case of the psychopathology general factor, it has been the psychotic symptoms as they are again the most impairing. Psychopathology researchers though have not interpreted the general factor as representing level of psychosis because it is apparent that the other disorders loading on this factor have nothing to do with being psychotic. It is perhaps similarly inaccurate to interpret the g-PD as a BPD factor because the other PDs loading on this factor have little to do with BPD. The prominence of the borderline symptoms on the general factor reflects their higher level of common im- pairment in occupational and social functioning (as well as distress) rather than the substantive content of these traits that are resulting in this impairment.

\section{Conclusions}

In sum, from the perspective of the FFM, both the Criterion A LPF and Criterion B traits are understood to be maladaptive variants of the FFM. The trait model involves all five FFM domains of neuroticism, introversion, openness/unconventionality, antagonism, and low conscientiousness (albeit rigid perfectionism would represent high conscientiousness). The identity self-deficit is understood to be a facet of neuroticism, whereas the selfdirectedness deficit would also involve aspects of low conscientiousness, empathy aspects of antagonism, and intimacy aspects of introversion (as well as neuroticism).

\section{Acknowledgment}

This paper is co-authored by Thomas A. Widiger and Gillian A. McCabe, with no additional individuals or organizations providing substantive contributions.

\section{Disclosure Statement}

The authors have no conflicts of interest to declare.

\section{Funding Sources}

There were no funding sources for this paper.

\section{Author Contributions}

This is a review paper prepared by Thomas A. Widiger and Gillian A. McCabe, both of whom made substantive contributions to the conceptualization and preparation of the manuscript.

\section{References}

1 American Psychiatric Association. Diagnostic and Statistical Manual of Mental Disorders. 5th ed. Washington: American Psychiatric Association; 2013.

2 Widiger TA, Gore WL, Crego C, Rojas SL, Oltmanns JR. Five factor model and personality disorder. In: Widiger TA, editor. The Oxford handbook of the five factor model. New York: Oxford University Press; 2017. pp. 449-78.

3 Widiger TA, Trull TJ. Plate tectonics in the classification of personality disorder: shifting to a dimensional model. Am Psychol. 2007 Feb-Mar;62(2):71-83.
4 Clark LA. Assessment and diagnosis of personality disorder: perennial issues and an emerging reconceptualization. Annu Rev Psychol. 2007;58(1):227-57.

5 Widiger TA, editor. The Oxford handbook of the five-factor model. New York: Oxford University Press; 2017.

6 Widiger TA, Crego C. The Five Factor Model of personality structure: an update. World Psychiatry. 2019 Oct;18(3):271-2.
7 Clark LA, Krueger RF. Rationale for a six-domain trait dimensional diagnostic system for personality disorder. Unpublished manuscript, 2010.

8 Livesley J. The DSM-5 personality disorder proposal and future directions in the diagnostic classification of personality disorder. Psychopathology. 2013;46(4):207-16.

9 Miller JD, Lynam DR. Missed opportunities in the DSM-5 Section III personality disorder model: commentary on "personality disorders are the vanguard of the post-DSM-5.0 era”. Pers Disord. 2013 Oct;4(4):365-6. 
10 Shedler J, Beck A, Fonagy P, Gabbard GO, Gunderson J, Kernberg O, et al. Personality disorders in DSM-5. Am J Psychiatry. 2010 Sep;167(9):1026-8.

11 Krueger RF, Markon KE. The role of the DSM-5 personality trait model in moving toward a quantitative and empirically based approach to classifying personality and psychopathology. Annu Rev Clin Psychol. 2014; 10(1):477-501.

12 De Raad B, Mlačić B. The lexical foundation of the Big Five factor model. In: Widiger TA, editor. The Oxford handbook of the five factor model. New York: Oxford University Press; 2017. pp. 191-216.

13 Livesley WJ. Conceptual and taxonomic issues. In: Livesley WJ, editor. Handbook of personality disorders. Theory, research, and treatment. New York: Guilford; 2001. pp. 3-38.

14 Samuel DB, Widiger TA. A meta-analytic review of the relationships between the five-factor model and DSM-IV-TR personality disorders: a facet level analysis. Clin Psychol Rev. 2008 Dec;28(8):1326-42.

15 Saulsman LM, Page AC. The five-factor model and personality disorder empirical literature: A meta-analytic review. Clin Psychol Rev. 2004 Jan;23(8):1055-85.

16 Crego C, Gore WL, Rojas SL, Widiger TA The discriminant (and convergent) validity of the Personality Inventory for DSM-5. Pers Disord. 2015 Oct;6(4):321-35.

17 Crego C, Oltmanns JR, Widiger TA. FFMPD scales: comparisons with the FFM, PID-5, and CAT-PD-SF. Psychol Assess. 2018 Jan;30(1): 62-73.

18 De Fruyt F, De Clercq B, De Bolle M, Wille B Markon K, Krueger RF. General and maladaptive traits in a five-factor framework for DSM-5 in a university student sample. Assessment. 2013 Jun;20(3):295-307.

19 DeYoung CG, Carey BE, Krueger RF, Ross SR. Ten aspects of the Big Five in the Personality Inventory for DSM-5. Pers Disord. 2016 Apr;7(2):113-23.

20 Gore WL, Widiger TA. The DSM-5 dimensional trait model and five-factor models of general personality. J Abnorm Psychol. 2013 Aug;122(3):816-21.

21 Griffin SA, Samuel DB. A closer look at the lower-order structure of the Personality Inventory for DSM-5: comparison with the Five-Factor Model. Pers Disord. 2014 Oct; 5(4):406-12.

22 Quilty LC, Ayearst L, Chmielewski M, Pollock BG, Bagby RM. The psychometric properties of the personality inventory for DSM-5 in an APA DSM-5 field trial sample. Assessment. 2013 Jun;20(3):362-9.

23 Thomas KM, Yalch MM, Krueger RF, Wright AG, Markon KE, Hopwood CJ. The convergent structure of DSM-5 personality trait facets and five-factor model trait domains. Assessment. 2013 Jun;20(3):308-11.

24 Watson D, Stasik SM, Ro E, Clark LA. Integrating normal and pathological personality: relating the DSM-5 trait-dimensional model to general traits of personality. Assessment. 2013 Jun;20(3):312-26.

25 Wright AG, Simms LJ. On the structure of personality disorder traits: conjoint analysis of the CAT-PD, PID-5, and NEO PI-3 trait models. Pers Disord. 2014;5(1):43-54.

26 Zimmermann J, Altenstein D, Krieger T, Holtforth MG, Pretsch J, Alexopoulos J, et al. The structure and correlates of self-reported DSM-5 maladaptive personality traits: findings from two German-speaking samples. J Pers Disord. 2014 Aug;28(4):518-40.

27 Watson D, Clark LA, Chmielewski M. Structures of personality and their relevance to psychopathology: II. Further articulation of a comprehensive unified trait structure. J Pers. 2008 Dec;76(6):1545-86.

28 Widiger TA, Crego C. HiTOP thought disorder, DSM-5 psychoticism, and five factor model openness. J Res Pers. 2019;80:72-7.

29 Costa PT, McCrae RR. Still stable after all these years: Personality as a key to some issues in adulthood and old age. In: Baltes PB, Brim OG, editors. Life span development and behavior. Volume 3. New York: Academic Press; 1980

30 Costa PT, McCrae RR. Revised NEO Personality Inventory (NEO PI-R) and NEO FiveFactor Inventory (NEO-FFI) professional manual. Odessa (FL): Psychological Assessment Resources; 1992.

31 Coker LA, Samuel DB, Widiger TA. Maladaptive personality functioning within the big five and the five-factor model. J Pers Disord. 2002 Oct; 16(5):385-401.

32 Piedmont RL, Sherman MF, Sherman NC, Dy-Liacco GS, Williams JE. Using the fivefactor model to identify a new personality disorder domain: the case for experiential permeability. J Pers Soc Psychol. 2009 Jun;96(6): 1245-58.

33 DeYoung CG, Quilty LC, Peterson JB. Between facets and domains: 10 aspects of the Big Five. J Pers Soc Psychol. 2007 Nov;93(5): $880-96$.

34 van Kampen D. The 5-Dimensional Personality Test (5DPT): relationships with two lexically based instruments and the validation of the absorption scale. J Pers Assess. 2012;94(1): 92-101.

35 Lee K, Ashton MC. Psychometric Properties of the HEXACO Personality Inventory. Multivariate Behav Res. 2004 Apr;39(2):329-58.

36 Tellegen A, Waller NG. Exploring personality through test construction: Development of the Multidimensional Personality Questionnaire. Unpublished manuscript, Minneapolis, Minnesota, 1987.

37 Tellegen A. Folk concepts and psychological concepts of personality and personality disorder. Psychol Inq. 1993;4(2):122-30.

38 Ashton MC, Lee K. Oddity, schizotypy/dissociation, and personality. J Pers. 2012 Feb; 80(1):113-34

39 Chmielewski M, Bagby RM, Markon K, Ring AJ, Ryder AG. Openness to experi- ence, intellect, schizotypal personality disorder, and psychoticism: resolving the controversy. J Pers Disord. 2014 Aug;28(4): 483-99.

40 Crego C, Widiger TA. The conceptualization and assessment of schizotypal traits: A comparison of the FFSI and PID-5. J Pers Disord. 2017 Oct;31(5):606-23.

41 Kemp KC, Burgin CR, Raulin ML, Kwapil TR. Using multiple measures of openness to experience to capture positive, negative, and disorganized dimensions of schizotypy. Pers Disord. 2019. [Epub ahead of print] https:// doi.org/10.1037/per0000389.

42 Moorman EL, Samuel DB. Representing schizotypal thinking with dimensional traits: A case for the Five Factor Schizotypal Inventory. Psychol Assess. 2018 Jan;30(1): 19-30.

43 Krueger RF, Derringer J, Markon KE, Watson $\mathrm{D}$, Skodol AE. Initial construction of a maladaptive personality trait model and inventory for DSM-5. Psychol Med. 2012 Sep;42(9): 1879-90.

44 Schneider K. Clinical psychopathology. New York: Grune \& Stratton; 1959.

45 Edmundson M, Lynam DR, Miller JD, Gore WL, Widiger TA. A five-factor measure of schizotypal personality traits. Assessment. 2011 Sep;18(3):321-34.

46 Goldberg LR, Johnson JA, Eber HW, Hogan $\mathrm{R}$, Ashton MC, Cloninger $\mathrm{C}$, et al. The international personality item pool and the future of public-domain personality measures. J Res Pers. 2006;40(1):84-96.

47 Crego C, Oltmanns JR, Widiger TA. Obtaining and losing the maladaptive bipolarity of the five-factor model. Pers Disord. 2020 Mar; 11(2):119-30.

48 Widiger TA, Crego C. The bipolarity of normal and abnormal personality structure: implications for assessment. Psychol Assess. 2019 Apr;31(4):420-31.

49 Bender DS, Morey LC, Skodol AE. Toward a model for assessing level of personality functioning in DSM-5, part I: a review of theory and methods. J Pers Assess. 2011 Jul;93(4): 332-46.

50 Hopwood CJ. A framework for treating DSM5 alternative model for personality disorder features. Pers Ment Health. 2018 May;12(2): 107-25.

51 Kernberg OF. Overview and critique of the classification of personality disorders proposed for DSM-V. Swiss Arch Neurol Psychiatr. 2012;163(07):234-8.

52 Few LR, Miller JD, Rothbaum AO, Meller S, Maples J, Terry DP, et al. Examination of the Section III DSM-5 diagnostic system for personality disorders in an outpatient clinical sample. J Abnorm Psychol. 2013 Nov; 122(4): 1057-69.

53 Clark LA, Ro E. Three-pronged assessment and diagnosis of personality disorder and its consequences: personality functioning, pathological traits, and psychosocial disability. Pers Disord. 2014 Jan;5(1):55-69. 
54 First MB, Bell CB, Cuthbert B, Krystal JH, Malison R, Offord DR, et al. Personality disorders and relational disorders: A research agenda for addressing crucial gaps in DSM. In: Kupfer DJ, First MB, Regier DA, editors. A research agenda for DSM-V. Washington (DC): American Psychiatric Association; 2002. pp. 123-99.

55 Krueger RF, Skodol AE, Livesley WJ, Shrout PE, Huang Y. Synthesizing dimensional and categorical approaches to personality disorders: refining the research agenda for DSMIV Axis II. In: Helzer JE, Kraemer HC, Krueger RF, Wittchen HU, Sirovatka PJ, Regier DA, editors. Dimensional approaches to diagnostic classification. Refining the research agenda for DSM-V. Washington (DC): American Psychiatric Association; 2008. pp. 85-100.

56 Widiger TA, Simonsen E. Alternative dimensional models of personality disorder: finding a common ground. J Pers Disord. 2005 Apr; 19(2):110-30.

57 Widiger TA, Bach B, Chmielewski M, Clark LA, DeYoung C, Hopwood CJ, et al. Criterion A of the AMPD in HiTOP. J Pers Assess. 2019 Jul-Aug;101(4):345-55.

58 Morey LC. Thoughts on the assessment of the DSM-5 alternative model for personality disorders: comment on Sleep et al. (2019). Psychol Assess. 2019 Oct;31(10):1192-9.

59 McCrae RR, Costa PT, Busch CM. Evaluating comprehensiveness in personality systems: the California Q-Set and the five-factor model. J Pers. 1986;54(2):430-46.
60 Mullins-Sweatt S, Widiger TA. The Shedler and Westen Assessment Procedure from the perspective of general personality structure. J Abnorm Psychol. 2007 Aug;116(3):618-23.

61 Skodol AE. Personality disorders in DSM-5. Annu Rev Clin Psychol. 2012;8(1):317-44.

62 Mullins-Sweatt SN, Edmundson M, SauerZavala S, Lynam DR, Miller JD, Widiger TA. Five-factor measure of borderline personality traits. J Pers Assess. 2012;94(5):475-87.

63 Livesley WJ, Jackson DN. Manual for the Dimensional Assessment of Personality Pathology-Basic Questionnaire. Port Huron (MI): Sigma Press; 2009.

64 Crego C, Widiger TA: The convergent, discriminant, and structural relationship of the DAPP-BQ and SNAP with the ICD-11, DSM5, and FFM trait models. Psychol Assess. 2020 Jan;32(1):18-28.

65 Zimmermann J, Kerber A, Rek K, Hopwood CJ, Krueger RF. A brief but comprehensive review of research on the Alternative DSM-5 Model for Personality Disorders. Curr Psychiatry Rep. 2019 Aug;21(9):92.

66 Bastiaansen L, De Fruyt F, Rossi G, Schotte C, Hofmans J. Personality disorder dysfunction versus traits: structural and conceptual issues. Pers Disord. 2013 Oct;4(4):293-303.

67 Berghuis H, Kamphuis JH, Verheul R. Specific personality traits and general personality dysfunction as predictors of the presence and severity of personality disorders in a clinical sample. J Pers Assess. 2014;96(4):410-6.
68 Sleep CE, Weiss B, Lynam DR, Miller JD. The DSM-5 Section III personality disorder Criterion $\mathrm{A}$ in relation to both pathological and general personality traits. Pers Disord. 2020 May;11(3):202-212.

69 McCabe GA, Widiger TA. A comprehensive comparison of the ICD-11 and DSM-5 section III personality disorder models. Psychol Assess. 2020 Jan;32(1):72-84.

70 Berghuis H, Kamphuis JH, Verheul R. Core features of personality disorder: differentiating general personality dysfunctioning from personality traits. J Pers Disord. 2012 Oct; 26(5):704-16.

71 Oltmanns JR, Widiger TA. Self-pathology, the five-factor model, and bloated specific factors: A cautionary tale. J Abnorm Psychol. 2016 Apr;125(3):423-34.

72 Sharp C, Wright AG, Fowler JC, Frueh BC Allen JG, Oldham J, et al. The structure of personality pathology: both general (' $\mathrm{g}$ ') and specific ('s') factors? J Abnorm Psychol. 2015 May;124(2):387-98.

73 Wright AG, Hopwood CJ, Skodol AE, Morey LC. Longitudinal validation of general and specific structural features of personality pathology. J Abnorm Psychol. 2016 Nov; 125(8): 1120-34.

74 Oltmanns JR, Smith GT, Oltmanns TF, Widiger TA. General factors of psychopathology, personality, and personality disorder: across domain comparisons. Clin Psychol Sci. 2018 Jul;6(4):581-9. 